\title{
The Influence of Paternalistic Leadership on the Development of Oriental Critical Thinking
}

\author{
Huilin Bai ${ }^{1,2} \&$ Hui-Ling Wendy Pan ${ }^{2}$ \\ ${ }^{1}$ Doctoral Program of Educational Leadership and Technology management, Department of Education and \\ Futures Design, Tamkang University, Taiwan \\ ${ }^{2}$ Graduate Institute of Educational Policy and Leadership, College of Education, Tamkang University, Taiwan \\ Correspondence: Hui-Ling Wendy Pan, Graduate Institute of Educational Policy and Leadership, College of \\ Education, Tamkang University, No.151 Yingzhuan Road, Tamsui District, New Taipei City 25137, Taiwan. \\ E-mail: panhlw@gmail.com
}

Received: November 22, 2021

Accepted: December 29, 2021

Online Published: January 13, 2022

doi:10.5539/ijbm.v17n2p56

URL: https://doi.org/10.5539/ijbm.v17n2p56

\begin{abstract}
In the context of globalization, critical thinking is still regarded as the core content of higher education. The difference between Eastern and Western cultures has a key impact on understanding critical thinking. When the current literature studies the influence of culture on critical thinking, it mainly considers from the macro level, mainly including ethnic history, traditional customs, religious beliefs, art, ethics, and so on. However, from a specific and micro cultural perspective, how critical thinking is influenced by a culture still lacks effective research. This paper studies the influence of Confucian paternalistic leadership on the development of critical thinking in the East from a specific cultural perspective. The study discovers that Asians are easier to understand how things change and they are more tolerant to conflict, which means that they see things as interrelated and interdependent. They are more likely to use intuitive and experience-based reasoning if there is a conflict between intuitive and logical reasoning. Benevolence and hierarchy in paternalistic leadership promote the formation of cooperative critical thinking in improving the operation of organizations so that the characteristics of oriental critical thinking can be analyzed more comprehensively.
\end{abstract}

Keywords: paternalistic leadership, oriental critical thinking, cultural difference

\section{Introduction}

Critical thinking is considered to be one of the core teaching objectives in higher education (Hong et al., 2020; Sigurðsson, 2017; Walker \& Finney, 1999). When regarding the formal reasoning skills, the definition of critical thinking is often included with searching evidence and criteria of logical arguments, the discussion from which surrounds with meeting specified standards of judging good thinking essentially (Lai, 2011; Lim, 1998). But in relating with judging in a reflective way what to do or what to believe, critical thinking processes are not only related to logical analysis but are more influenced by social and power relationships (Kaplan, 1994). The acquisition of the competence to participate critically in communities and social practices may sway a person's judgment, which is shaped by a combination of historical, institutional, moral, and sociocultural conditions (Beach, 2020; Brown, 2018; Ten Dam \& Volman, 2004). The study also finds that critical thinking has a close relationship with the context of culture, which involves geographic position, history, worldview, and complex interpersonal communication (Brown, 2018; Hong et al., 2020; Shiraev \& Levy, 2020; Taimur \& Sattar, 2020). Critical thinking has social and political dimensions, and the differences between Eastern and Western cultures play a key role in this (Walters, 1994). Therefore, the socio-cultural dimension of critical thinking has moral as well as cultural characteristics.

Affected by Eastern culture, the development of critical thinking in the East represented by China shows unique characteristics different from Western critical thinking. Ever since Dong Zhongshu proposed to "Ban from hundred philosophers, venerate Confucianism" during the Emperor Wu of the Han Dynasty (156-87BC), Confucianism is a core component of Chinese culture, which has influenced China for more than 2,500 years. Confucianism developed the conception of the "three cardinal guides" (ruler guides subject, father guides son, and husband guides wife) and the "five constant virtues" (benevolence, righteousness, propriety, wisdom, and fidelity), which was considered as basic rules for dealing with the relationship between the monarch and 
ministers, father and son, husband and wife as well as senior and inferior. Chinese Confucian philosophy is very important for understanding paternalistic leadership, which is also an important concept and content in traditional Chinese Confucian philosophy (Farth et al., 1998). In both the East and the West, the family is considered the smallest unit of state organization, and paternalistic leadership is inextricably linked to the family model (Aycan, 2006). Influenced by cultural traditions from Chinese Confucianism, paternalistic leadership limits the development of critical thinking under the characteristic of inherited authoritarian obedience from clear boundaries of Chinese family members, which is thought to curb the cultivation of capability about the doubt to a certain extent (Lau et al., 2020a). In Mansur's (2017) opinion, paternalistic leadership is equivalent to authoritarianism, whose indisputable power would greatly damage the independent thinking ability of subordinates (Mansur et al., 2017). But at the same time, close family member relationships are the foundation of paternalistic leadership, which emphasizes the central position of the vertical relationship between superiors and subordinates. Therefore, paternalistic leadership is seen as a top-down hierarchy based on morality, kindness, and obedience to authority, whose critique in context is more reflected as the form of self-reflection critically rather than barely demonstrating critical thinking with the ability to make sound logical arguments (Bedi, 2020). In contrast, critical thinking in the Confucian tradition focuses on inducing group-level critical thinking so that good judgment could be rendered under learning experience from practical organizational conditions (Hofstede et al., 2005). How to understand characteristics of Eastern critical thinking in a specific environment is contributed to figuring out the presentation of critical thinking in particular cultural circumstances. The Confucian paternalistic leadership that has run through China for 2500 years is an important and specific environment that Eastern critical thinking cannot ignore.

Through a questionnaire survey, Kelly Y.L. Ku (2010) studied the relative and combined effect of critical thinking on 137 Chinese college students from the aspects of cognitive demand, experience openness, and truth scale, and the results showed that cultural factors of Critical thinking in China were significantly correlated $(\mathrm{Ku}$ \& Ho, 2010). Through in-depth interviews, Kathy Durkin (2008) studied the experience of adapting east Asian master's students in the UK to the academic norms of western critical thinking and debate and found that most students integrated their own critical thinking with western critical thinking and debate (Durkin, 2008a). Through experimental studies in education, Charlene Tan investigated the existence and significance of communitarian practices of critical thinking in Asian cultures (Adetunji et al., 2021). Through literature induction, this paper attempts to interpret the relationship between critical thinking and Eastern culture from the perspective of paternalistic leadership.

This article hopes to clarify the influence of Confucian paternalistic leadership on Eastern critical thinking by analyzing the cultural concepts behind the organizational structure in paternalistic leadership. The main content of the research in this article includes: the core content of paternalistic leadership, its cultural connotation and its relationship with critical thinking; The influence of different modes of paternalistic leadership on the development of critical thinking; Paternalistic leadership affects the differences between the East and the West in critical thinking; Paternalistic leadership promotes the emergence and development of collaborative critical thinking.

\section{Literature Review}

\subsection{Paternalistic Leadership and Eastern Critical Thinking Concepts}

Paternalistic leadership is regarded as a new research field in leadership research. As a concept of governance, paternalism is often described as a legitimate authority and is regarded as one of the most basic types of traditional governance (Lau et al., 2019). The integration of Confucianism and legalism in China has gradually led to the politicization of Confucianism and the absolute legal power and authority of superiors over subordinates in the management system. At the same time, Confucianism also regulated the way of different roles in social relationships, including father-son relationships and courtier relationships, emphasizing that superior love followers and subordinates should respect superiors (Arun et al., 2021). This form of reciprocity maintains a harmonious "human relationship" that combines strong discipline with a culture of authority and paternal kindness and moral traits to form the original model of paternalistic leadership.

Critical thinking is first advocated by philosophers such as Socrates, who encouraged followers to explore and emphasized that the final result of the analysis of facts is not often what it appears on the surface. A full discussion of the risks of decisions is the natural foundation for the development of critical thinking. Because it is a way of forming ability in the process of exploring problems, and also a reflection of thinking to test the cognitive flexibility, and judgment of individuals in the organization (Natale \& Ricci, 2006). 


\subsection{Paternalistic Leadership: A Brief Review}

Paternalistic leadership framework, as a model of leadership in the study of local organization behavior in China, has gradually received attention from Chinese and Western researchers, which because leadership styles will be deeply influenced by local culture and traditions, and the presentation of local culture and way of thinking needs to construct a rich theory of historical and cultural connotation, which provides the research process of understanding organization management and leadership behavior. Kelloway and Gilbert (2017) considered that the local psychological process of different cultural formations will form a fundamental cognition of social change and organizational structure, which is similar to the socio-cultural environment and also includes hierarchical structure and role distribution. He believed that the study of the organizational structure of leadership needs to consider cultural factors. The researchers mentioned that in relevant studies that the behavior of leaders in the performance of roles in their environmental background, and among the three dimensions presented by paternalistic leadership, it is the balance of the relationship between superiors and subordinates maintained by the transformation of roles (Kelloway \& Gilbert, 2017). In an in-depth study of the historical and cultural foundations of paternalism. There are three key elements of paternalism: authoritarian, benevolent, and moral leadership, whose discussion is based on the traditional ideological sources of Chinese Confucianism and legalism, considering the leadership style similar to patriarchy (Sposato, 2019). The clear and powerful authoritative leadership style is combined with the elements of kindness and morality. The authoritarian dimension mainly focuses on the habit of leaders to instruct their subordinates in a didactic way. The benevolent dimension reflects the leader's comprehensive attention to subordinates, and the subordinates' gratitude and reciprocating behavior. The moral dimension lies in the leader showing outstanding personal virtues, guiding the organization's management effectively through setting a moral example and making subordinates respect and identify (Lau et al., 2020b).

In the research process of organization culture, the formation of thinking and cognition mode brought by the national culture embedded in it plays an important role in the formation of organizational management structure. In the long history of China, leaders maintained strong authority and strictly controlled followers, which virtually highlighted the vertical relationship between superiors and subordinates as the central organizational model, and authoritarian culture was bred. At the same time, based on Confucian orthodox thought and people-oriented thought, subordinates and followers form the obligatory gratitude mentality in moral teaching (Lin et al., 2019; Pellegrini et al., 2010).

\subsection{Oriental Critical Thinking: A Brief Review}

The study of critical thinking has always been the content of interest of western researchers. There are at least seven definitions of critical thinking. Tim (2013) expands the interpretation process of critical thinking in different cultural backgrounds, which effectively provides evidence that the meaning of critical thinking in different cultures needs to consider more situational and contextual factors (Moore, 2013). Graham (2011) proposed the presence of critical thinking in the context of Chinese traditional culture and social development, and gave extremely detailed evidence of the existence of critical thinking in various ancient books of Chinese culture, especially when it comes to logic and judgment factor analysis, his research effectively supports the existence of critical thinking in organizational structure in Chinese history (Tian \& Low, 2011).

For a long time, the construction of critical thinking has been formed and developed under the western philosophical tradition. It is often regarded as a set of cognitive thinking skills, which can improve thinking through rational analysis and reasoning analysis, and evaluation to make better judgments (Chen \& Creativity, 2017). However, the skills formed by judgment have a different interpretation in different cultural concepts, and the results presented need to be understood and explained in different cultural backgrounds. The inherent bias against eastern culture may lead to a biased interpretation of the concept of critical thinking. Literature shows that the Confucian culture also has the display mode of critical thinking (Tan, 2017a). In the process of making a judgment, specific action situations need to be considered. When helping to make a judgment, the general knowledge structure and norms need to be changed through the real context and situation. This is very different from the concept of critical thinking as understood in western culture (Tan, 2017b). The interpretation of critical thinking in the eastern dimension provides a new perspective for the effectiveness of paternalistic leadership organizational structure. 


\subsection{The Cultural Connotation of the Core Content of Paternalistic Leadership and Its Relationship with Critical Thinking}

\subsubsection{The Thinking Philosophy View of Paternalistic Leadership}

According to social dominance theory (Sidanius \& Pratto, 2001) and social exchange theory to explain the influence of paternalistic leadership on followers' work results, all human societies are based on the social rank of the group(Blau, 1968; Sidanius \& Pratto, 2001). These social hierarchies may provide one group with status over another and allow one group to dominate the other (Levin, 2004; Sidanius et al., 2000). Paternalistic leadership enjoys dominance over subordinates because paternalistic leadership systems provide higher organizational status for leaders. Paternalistic leaders exert significant influence on their members and directly influence their decision-making process (Cheng et al., 2004; Tsui et al., 2004). On the other hand, followers of paternalistic leadership generally respect their leader's decisions and are willing to submit to the leader's will (Aycan, 2006). In Confucian culture, the existence of the mode of a supervisor-subordinate relationship largely pays more attention to group goals in common. Members of paternalistic leadership see themselves as a part of social relationships, who emphasizes connectedness and interdependence. The trust of members is the premise for the leader to play the role of the team, and the patriarchal leader is also constrained, so the patriarchal leader often shows the duality of control and kindness. which can be explained by the Oriental yin-yang philosophy (Wu et al., 2012). The philosophy of Yin and Yang is a holistic, dynamic, and dialectical view of the world, emphasizing the interdependence and coexistence of the two opposing cosmic energies of Yin and Yang. According to this philosophy, although family leadership and membership may seem antagonistic and contradictory, if groups are to function, they are complementary and must be combined into a unified whole (Fang, 2012). When applied to paternalistic leadership, scholars have argued that the seemingly antagonistic and contradictory elements of authoritarian benevolence and moral leadership coexist as the Yin and Yang sides: they have an opposite effect on follower results, but interact and complement each other to form an integral part of paternalistic leadership (Wu et al., 2012). Following the social interdependence model, it is the sense of interaction that creates a positive learning atmosphere in which the dialogue form supervisor and subordinates stimulate their continuous elaboration of ideas so that the circumstance of free-thinking and dissent could generate critical thinking. Most empirical studies of paternalistic leadership have been conducted in cultures where Confucianism and Yin-Yang harmony philosophies inspire oppositional leadership behaviors to coexist and integrate into larger paternalistic leadership structures (Chen, 2002; Wu, 2012). According to social exchange theory, the efforts of members should also be rewarded by paternalistic leadership, which can also explain the reasons for the internal balance between paternalistic leadership and members.

\subsubsection{Critical Thinking in Chinese Traditional Confucianism Philosophy}

The critical thinking in Confucianism advocates the use of transformative self-critical attitudes to obtain new judgments on things (Sigurðsson, 2017). Early political leaders in China have realized the importance of a sustained critical attitude for individuals to play their corresponding social roles. There are two main thinking orientations: authority-minded and harmony-minded, which are mainly the reflection of thinking based on morality, that is, the process of treating the person with the highest qualifications and the most knowledge as the arbiter of judgments of things. For leaders, it is a process of continuous self-renewal and criticism (Kim, 2002; Nisbett, 2004). Because of the respect and admiration of the subordinates for the leader, he needs to constantly examine his words and deeds, and this mode of behavior invisibly promotes the continuous improvement of the self. Secondly, only by continuously enriching one's knowledge, conducting serious inquiry and reflection, soliciting the opinions from other people, and accepting reasonable criticism can we have new insights. And this kind of self-critical experience often requires a real practice process, during which continuous self-reflection and this kind of participation process itself is the embodiment of a kind of critical thinking. The process of self-reflection is to integrate knowledge through a more logical process and enhance the accuracy of things judgment in the process of practice (Peng \& Nisbett, 2000). In addition, the process of self-reflection requires active listening to others to modify one's own beliefs, so this transformative self-critical attitude will enhance the group's ability to make logical judgments about things.

Therefore, to explain and understand the typical oriental thinking process from the point of view of Chinese native philosophy can be better distinguished from the western concept of contradiction, which emphasizes the conflict and reasoning process necessary for resolving contradictions (Nisbett, 2004). Compared with the West, the ability of self-criticism contributes to Asians being easier to understand change and more tolerant of contradiction, mainly because they believe that things are interrelated and interdependent. These three characteristics of the Asian way of thinking are inconsistent with the dominant tradition of formal logic thinking in Western culture. 
Kim (2002) found that Westerners tend to use formal logical rules in reasoning, while East Asians tend to use intuitive and experience-based reasoning when there is a conflict between intuitive and formal reasoning strategies (Kim, 2002). A preference for dialectical thinking may drive Asian students to be more inclined than Western students to seek a middle way between apparent contradictions and to choose intuitive reasoning over formal reasoning (Peng \& Nisbett, 2000).

\subsubsection{The Influence of Different Modes of Paternalistic Leadership on the Development of Critical Thinking}

Paternalistic leadership mainly enhances the ability to apply knowledge content based on personal experience and to think and judge the previous leadership process through self-reflection in practice. According to Guthrie and King (2004), the capability of self-reflection is a key component of developing leadership (Guthrie \& King, 2004). Under paternalistic leadership, the mutual interaction of accumulated experience and knowledge will be helpful for members to improve their self-reflective ability because of the harmonious working environment between superiors and subordinates being preserved, in which the chance will be created to dialogue with others smoothly so that a deep knowledge of oneself might be realized (Paul, 1981). Based on research from cognitive psychology, the model style of authoritarianism and benevolence from paternalistic leadership is founded in the perspective of moral leadership (Martin, 1992), which means that critical thinking relies solely on reason is not enough to explain its presence in the realm of the process of social practice (Phelan, 2001). The interdependent psychology impacted from collectivist culture places a strong emphasis on building co-existence and paragenetic relations with an inherent dynamic-interacting activity, which will stand a chance of truly moving a discussion of critical thinking to a new level of understanding when connecting the practice of thinking critically (Chin et al., 2018; Mason, 2008). The significant characteristics of paternalistic leadership emphasize that the cultivation of individual virtues from leaders, which should be considered as the most effective for governing because on the one hand, the presentation of authoritarian leadership implement that how leadership is in charge, which means that the process of authoritative hierarchic-bureaucratic organization descending from traditional Chinese family reserves the normative standards of handling with issues and social relationship (Farh \& Cheng, 2000; E. K. Pellegrini \& T. A. J. J. o. m. Scandura, 2008). On the other hand, benevolent leadership is based on the principle of reciprocity, which will promote intrinsic working motivation for subordinates to search for more reasonable solutions and superordinate leaders will also adjust organizational procedures to search for more effective mechanisms (Novelli Jr \& Taylor, 1993). Mutual inspiration and motivation provide an opportunity to improve personal cognitive and behavioral flexibility, which is considered as the feature most related to critical thinking ability because this model of leadership emphasizes self-reflection from the practical learning experience, and to some degree, it can support the way of appropriate feedback mechanism to continually reexamine behaviors when looking critical thinking as a conception in relation to the thinking in practice (Braver et al., 2014; Paul \& Elder, 2014). It is noteworthy that critical thinking is not neutral and objective because it is a tool, which has no life on its own, and it only has meaning and purpose when it is used by people, so reasonable judgments and logical reasoning will be influenced by different cultural norms in space and time (Nisbett et al., 2001), and therefore the definition of critical thinking needs to be expended because of the nature of inherent dynamic -interacting from different situations in reality (Elder \& Paul, 2020; Haidt, 2001). And further, as an important dimension of paternalistic leadership, the main purpose of moral leadership in practical social interaction tends to build employees' conscious formation of disposition quality including openness, compassion, respect and tolerance through moral principle, moral examples and moral persuasion (Korac-Kakabadse et al., 2001). In essentially, nurturing growth in intellectual character virtues provides the ability and willingness to consider fully and conscientiously the viewpoints from others with whom they initially disagree, which means that paternalistic leadership is helpful to get out of a personal mindset under the influence of setting up moral principle, moral examples and moral persuasion (Baehr, 2015) because the one is willing and able to take up a different cognitive standpoint, which identifies the learning process of essential critical thinking skills needs to search the correct direction and strength of thinking based on motivated thinking dispositions (Bénabou et al., 2019; Nickerson, 2007).

The three models of paternalistic leadership provide clear and complete affective and normative consideration to demonstrate critical thinking is viewed as a practice. The models of authoritarian leadership and benevolent leadership reflect the dynamic relationship between paternalistic leadership and subordinates' responses, whose behavior connotation not only specifies the subordinates the established code of conduct but also releases the space for individuals to show flexible independent thinking (Bai et al., 2019). Respect for tradition, the practice of etiquette, and respect for authority figures are conducive to the formation of a social model of intimacy (Atkinson, 1997; Durkin, 2008b; Misco, 2013). The personal virtues of leaders and their social models, as the carriers of influence between leaders and subordinates, will have a direct effect on subordinates' cognition. 
Therefore, it can be considered that paternalism plays a role in specific cultural contexts and situations. To some extent, leaders exhibit (benevolent) paternalistic attitudes and behaviors toward their subordinates as a function of effective relationships to maintain trust (Chen et al., 2014). Pellegrini and Scandura (2008) believed that there is an exchange relationship between paternalism and leadership members. Since patriarchal leadership is highly individualized, it also depends on the quality of the relationship between individuals and subordinates. Under the influence of this model, paternalistic leadership provides care, support, and protection to its members by influencing the behaviors of subordinates through practices. To a certain extent, problems can be found in time to improve problems in time (E. K. Pellegrini \& T. A. Scandura, 2008). This kind of leadership model is influenced by the value of collectivism. The thinking mode and behavior mode formed in this context emphasizes the ability to solve problems in practice and make reasonable judgments through the accumulated experience (Gelfand et al., 2007).

\subsubsection{Paternalistic Leadership Influences the Differences Between the East and West in Critical Thinking}

The cultural embeddedness of critical thinking is based on the assumption that thinking is always contextually relevant. Rational evidence as a standard for critical thinking necessarily relies on historically specific language and practice and takes place in a specific cultural context in response to a specific situation (Maxcy, 1985). No opinion is born out of thin air, for all opinions originate from and are influenced by specific historical economic, and social conditions (Smeyers \& Marshall, 1995). Critical thinking is not only an independent and universal skill but also a practice Bailin et al. (1999) states that the standards and principles of critical thinking are cultural artifacts (Bailin et al., 1999). The individualistic tendency in Europe and the United States is believed to promote the development of critical thinking and the diversity of viewpoints is respected and effectively valued (Hofstede et al., 2005). When a situation calls for judgment, good thinking is an analysis based on objective standards of the reason that treats different opinions in a fairway. In the practice of paternalistic leadership, if one wants to exercise independent judgment, opinions may arise that are incompatible with the prevailing mood. In a society that prioritizes consensus and avoids debate, paternalistic leadership distinguishes the adversarial nature of logical critical thinking from empathic interpersonal relationships and connecting styles and expects to make decisions and solve problems through collaborative rather than confrontational critical thinking in different situations (Ennis, 1992; Halpern, 1998).

In paternalistic leadership, while imposing strict discipline and high-performance standards on subordinates, leaders give strict guidance and instructions to subordinates, to promote their dependence and obedience. Such kind of leadership by example is expected to increase external motivation and compliance by setting high standards and providing guidance to subordinates. This model of work through practice does not use reasoning and logical rules, but rather tends to use intuition and experience-based reasoning to solve problems. Cultural psychology has shown that Asians use different problem-solving skills than Western participants on different tasks because East Asians are more likely to solve problems contextually, while European Americans are more likely to focus solely on the problem and ignore the situation when completing frame-line tasks (Ji et al., 2000).

\subsubsection{Paternalistic Leadership Promotes the Emergence and Development of Collaborative Critical Thinking}

Through the social experience accumulated in specific cultural and historical practices, critical thinking tends to be more active. This is mainly because interpersonal communication is rooted in the specific cultural context supported by history, system, and morality, and constitutes the presentation mode of cooperative critical thinking in Eastern culture (Fishman, 1988). This means that the judgment characteristics of oriental critical thinking on things need to examine the quality characteristics of practitioners themselves because practitioners with excellent qualities are often able to promote the solution of things from positive aspects, rather than simply relying on a set of fixed logical reasoning standards to conclude things. This process is achieved through continuous cooperation and contact, which requires a willingness to be open to each other's opinions and a tendency to be tolerant of various possibilities (Facione \& Facione, 1996) rather than using confrontation to get to the right conclusion (Durkin, 2008b). In paternalistic leadership, the leader, as the main authority figure, the psychological and behavioral expression from whom play an important role in influencing the thinking model of subordinates because the organizational construction of paternalistic leadership is a clear relationship between superiors and subordinates, the close ties of interdependence from whom needs to construct group-mediated learning so that improve their ability of self-reflection and self-assessment from a dynamically changing context of a conversation in microanalysis, which provides powerful interpretation to illustrate the individual process of critical thinking, that is occurring-reflection in action-observation-changes in practice-self-assessment after action (Schön, 1938). However, the activities from the self-reflection give more consideration to regard critical thinking as a combination of being intellectual and affective in which individuals have motivation in action to explore new understanding and appreciation to experience and knowledge from biliteral social interaction, which 
creates opportunities for each other to achieve new judgment in the collaborative critical thinking processes (Yukawa, 2006). The duality between benevolence and authoritarianism in paternalistic leadership, as two traditional cultural norms, is mainly embraced from the logic of being holistic, dynamic to handle issues, the practical social experience derived from which focuses on expressing and assessing the leadership process in reality, which identifies that the possibility of accurate judging is based on an enriched understanding from multiple perspectives to situations (Lin et al., 2018). In addition, the style of benevolence and authority embedded in paternalistic leadership are interdependent in correcting erroneous judgments brought from prejudice because the genuine concern from leaders contributes to creating an adjustable working environment for subordinates, who are given more motivation to take action effectively so that they are exercised how to thinking critically and comprehensively in such stable organization (Dixon et al., 2012; Fox, 1997; Moore, 2010). The style of moral leadership is dominant for creating principles of democratic dialogue because of which sets up correct orientation and essential significance to determine how to cultivate our cognition incorrect way, which lay the foundation for considering the practical meaning of critical thinking, as well as the trust and admiration from the following of subordinates to the leaders, improve the efficiency of current practices in organizational operation and enhancement in organizational adaptability (Liu et al., 2010). The three leadership models embedded in paternalistic leadership create an organizational climate that fosters lasting mutually beneficial and harmonious relationships between the superior leaders and subordinates, affective trust derives from which is regarded as a critical mediating mechanism to maintain positive emotions on both sides where the individuals are willing to put forward new perspectives and considerations without fear of being reprimanded or ridiculed (Nisbett et al., 2001). The subordinates who are encouraged by leaders' trust and care significantly increase their organizational identification, which will help to turn into a positive attitude and courage to cultivate their open-minded thinking in an aspect of sharing their ideas and opinions in a relaxing environment (Hou et al., 2019). The high moral standards and integrity of superior leaders give good examples for followers, which is the foundation to make objective and sound judgments under the construction of harmonious and benignant bilateral relationships so that the disposition of being intellectually curious can be stimulated. This model of reciprocity based on the relationship improves one's reasoning ability by considering different viewpoints because in this relationship model, out of respect for leaders, subordinates will diligently collect relevant information sources in the process of dealing with problems, take the initiative to think and analyze problems, reasonably choose the criteria for judging problems, and finally make judgments cautiously (Wu et al., 2012). In this process, the leader will restrain his behavior more because of the trust of his subordinates. A positive attitude from leaders is also an important factor for subordinates to actively participate in thinking. Under this reciprocity mode, leaders and subordinates show more active thinking willingness and tendency due to their affirmation from each other (Tyler \& Blader, 2003).

The attitude of the leader will firstly increase the motivation of the subordinates emotionally, which helps the subordinates' tendency to think critically. The cultural norms related to benevolence in paternalistic leadership are based on the model of reciprocity. The leader increases the trust of his subordinates through his behavior, aiming to seek the coordination of both positions so that both sides can benefit from it. The cooperative critical thinking advocated by Durkin (2008) takes maintaining the dignity of both parties and the harmony of the relationship as the starting point, and presents the reasoning process appropriately completely, avoiding making judgments through direct conflicts as far as possible, a soft "middle way" approach adopted from which also involves the critical thinking process of independent thinking and analysis, but its way of communication is not antagonistic as the main communication mode (Durkin, 2008b; Waller, 2012). Collaborative critical thinking is action-oriented, and it intends to obtain more sources of information in the process of solving a problem to make a better judgment rather than get caught up in exploring the weaknesses of the other side's argument to win the final debate. Besides, the hierarchy of paternalistic leadership and reciprocal mode, when the leader's behavior and accepted as subordinate real quality, the subordinates will pay more attention to the opinions of the leader, the analysis process will be more careful, the problem of the leaders often because subordinates attitude change action will be taken to promote the improvement of the overall treatment and welfare, to subordinates for greater rights.

To grasp a reasonable judgment of things is to make a correct judgment of things in a specific practical environment by considering the actual contextual background through a series of specific practical activities. In the process of judging things, critical thinking needs to distinguish the tendency of critical thinking from cognitive ability, to realize the application of knowledge and skills in actual situations to flexibly and reasonably make judgments according to different situations. 


\section{Conclusion}

The result from this study has two major contributions. The first is the paternalistic leadership influenced by Chinese traditional Confucianism enriches people's understanding of collaborative critical thinking, which enlarges the conventional notions and presupposition of the definition from the West. The research of paternalistic leadership provides a micro and concrete perspective to illustrate that critical thinking in the East gives major consideration to maintain a hierarchical and harmonious social relationship, the purpose of which does not rebel against establishing traditional structures of knowledge and authority but nurtures the ability of critical thinking in a moderate way. The three dimensions of paternalistic leadership discussed in this paper (benevolence, authoritarianism, and moral) presents typical communitarian ideology in Asia, which means that criteria of critical thinking in the East are accumulated from the mutual learning experience, which guides us to improve our judgment in practice. Critical thinking embedded with an affirmation of the communal action means that the organization constituted through common nationality and culture provides universal values and norms to confirm the result brought from critical thinking provides the beneficial solution in reality. In addition, the organizational structure of paternalistic leadership emphasizes the leading process is in accordance with ethical constraints rather than merely logical reasoning in de-contextualization. Secondly, the detailed research of paternalistic leadership reminds us of the process of self-reflection filling in the blank for understanding the critical thinking of the East, which values the motivation and disposition to think critically spontaneously for exploring an appropriate solution. The way of creating a discursive space between superiors and subordinates brings to the fore the existence and presentation of collaborative critical thinking in collegial and communitarian Asia contexts.

\section{References}

Adetunji, O. R., Ashimolowo, R. A., Aiyedun, P. O., Adesusi, O. M., Adeyemi, H. O., \& Oloyede, O. R. (2021). Tensile, hardness and microstructural properties of $\mathrm{Sn}-\mathrm{Pb}$ solder alloys. Materials Today: Proceedings, 44, 321-325. https://doi.org/10.1016/j.matpr.2020.09.656

Arun, K., Gedik, N. K., Okun, O., \& Sen, C. (2021). Impact of cultural values on leadership roles and paternalistic style from the role theory perspective. World Journal of Entrepreneurship, Management Sustainable Development. https://doi.org/https://doi.org/10.1108/WJEMSD-10-2020-0128

Atkinson, D. (1997). A critical approach to critical thinking in TESOL. TESOL quarterly, 31(1), 71-94. https://doi.org/https://doi.org/10.2307/3587975

Aycan, Z. (2006). Paternalism: Towards conceptual refinement and operationalization. Scientific Advances an Indigenous Psychologies: Empirical, Philosophical, Cultural Contributions, 4-45. https://doi.org/https://doi.org/10.1007/0-387-28662-4_20

Baehr, J. (2015). Intellectual virtues and education: Essays in applied virtue epistemology. Routledge.

Bai, S., Lu, F., \& Liu, D. (2019). Subordinates' responses to paternalistic leadership according to leader level. Social Behavior Personality: an international journal 47(11), 1-14. https://doi.org/https://doi.org/10.2224/sbp.8430

Bailin, S., Case, R., Coombs, J. R., \& Daniels, L. B. (1999). Conceptualizing critical thinking. Journal of Curriculum Studies, 31(3), 285-302. https://doi.org/10.1080/002202799183133

Beach, D. (2020). Maybe one in a hundred or one in a thousand in the neoliberal, new-managerial university! Aesthetics of experience and the question of transgressive critical thinking. Ethnography Education and Information Technologies, 1-14.

Bedi, A. (2020). A meta-analytic review of paternalistic leadership. Journal of Applied Psychology, 69(3), 960-1008. https://doi.org/https://doi.org/10.1080/17457823.2020.1719856

Bénabou, R., Falk, A., \& Tirole, J. (2019). Narratives, imperatives, and moral persuasion (NBER working paper, Issue.

Blau, P. M. (1968). Social exchange. International encyclopedia of the social sciences, 7, 452-457. https://doi.org/https://doi.org/10.1080/17457823.2020.1719856

Braver, T. S., Krug, M. K., Chiew, K. S., Kool, W., Westbrook, J. A., Clement, N. J., Adcock, R. A., Barch, D. M., Botvinick, M. M., \& Carver, C. S. (2014). Mechanisms of motivation-cognition interaction: challenges and opportunities. Cognitive, Affective, Behavioral Neuroscience, 14(2), 443-472. https://doi.org/https://doi.org/10.3758/s13415-014-0300-0 
Brown, K. (2018). Education, culture and critical thinking. Routledge.

Chen, L., \& Creativity. (2017). Understanding critical thinking in Chinese sociocultural contexts: A case study in a Chinese college. Thinking Skills, 24, 140-151. https://doi.org/https://doi.org/10.1016/j.tsc.2017.02.015

Chen, M. (2002). Transcending paradox: The Chinese "middle way" perspective. Journal of Asia Pacific Journal of Management, 19(2-3), 179-199. https://doi.org/https://doi.org/10.1023/A:1016235517735

Chen, X. P., Eberly, M. B., Chiang, T. J., Farh, J. L., \& Cheng, B. S. (2014). Affective trust in Chinese leaders: Linking paternalistic leadership to employee performance. Journal of management, 40(3), 796-819. https://doi.org/https://doi.org/10.1177/0149206311410604

Cheng, B. S., Chou, L. F., Wu, T. Y., Huang, M. P., \& Farh, J. L. (2004). Paternalistic leadership and subordinate responses: Establishing a leadership model in Chinese organizations. Asian Journal of Social Psychology, 7(1), 89-117. https://doi.org/https://doi.org/10.1111/j.1467-839X.2004.00137.x

Chin, T., Rowley, C., Redding, G., \& Wang, S. (2018). Chinese strategic thinking on competitive conflict: insights from Yin-Yang harmony cognition. International Journal of Conflict Management. https://doi.org/https://doi.org/10.1108/IJCMA-09-2017-0101

Dixon, J., Levine, M., Reicher, S., \& Durrheim, K. (2012). Beyond prejudice: Relational inequality, collective action, and social change revisited. Behavioral Brain Sciences 35(6), 451. https://doi.org/10.1017/S0140525X12001550

Durkin, K. (2008a). The adaptation of East Asian masters students to western norms of critical thinking and argumentation in the UK. Intercultural Education, 19(1), 15-27. https://doi.org/https://doi.org/10.1080/14675980701852228

Elder, L., \& Paul, R. (2020). Critical thinking: Tools for taking charge of your learning and your life. Foundation for Critical Thinking.

Ennis, R. H. (1992). Conflicting views on teaching critical reasoning. Journal of Critical reasoning in contemporary culture, 5-27.

Facione, N. C., \& Facione, P. (1996). Externalizing the critical thinking in knowledge development and clinical judgment. Nursing Outlook, 44(3), 129-136.

Fang, T. (2012). Yin Yang: A new perspective on culture. Journal of Management Organization Review, 8(1), 25-50. https://doi.org/https://doi.org/10.1111/j.1740-8784.2011.00221.x

Farh, J.-L., \& Cheng, B.-S. (2000). A cultural analysis of paternalistic leadership in Chinese organizations. In Management and organizations in the Chinese context (pp. 84-127). Springer. https://doi.org/https://doi.org/10.1057/9780230511590_5

Farth, J.-1., Leong, F. T., \& Law, K. S. (1998). Cross-cultural validity of Holland's model in Hong Kong. Journal of vocational behavior, 52(3), 425-440. https://doi.org/https://doi.org/10.1006/jvbe.1997.1631

Fishman, A. (1988). Amish Literacy: What and How It Means. ERIC.

Fox, R. A. (1997). Confucian and communitarian responses to liberal democracy. The Review of Politics, 561-592. https://doi.org/https://doi.org/10.1017/S0034670500027728

Gelfand, M. J., Erez, M., \& Aycan, Z. (2007). Cross-cultural organizational behavior. Annu. Rev. Psychol, 58, 479-514. https://doi.org/https://doi.org/10.1146/annurev.psych.58.110405.085559

Guthrie, V. A., \& King, S. (2004). Feedback-intensive programs. Journal of The Center for Creative Leadership handbook of leadership development, 2.

Haidt, J. (2001). The emotional dog and its rational tail: a social intuitionist approach to moral judgment. Psychological review 108(4), 814. https://doi.org/https://doi.org/10.1037/0033-295X.108.4.814

Halpern, D. F. (1998). Teaching critical thinking for transfer across domains: Disposition, skills, structure training, and metacognitive monitoring. Journal of American psychologist, 53(4), 449. https://doi.org/https://doi.org/10.1037/0003-066X.53.4.449

Hofstede, G. H., Hofstede, G. J., \& Minkov, M. (2005). Cultures and organizations: Software of the mind (Vol. 2). Mcgraw-hill New York. 
Hong, L., Sandaran, S., \& Fang, W. (2020). Intercultural communication competence with critical thinking on foreign language teaching in universities under globalization. Journal of Critical Reviews, 7(11), 627-630. https://doi.org/ http://dx.doi.org/10.31838/jcr.07.11.114

Hou, B., Hong, J., Zhu, K., \& Zhou, Y. (2019). Paternalistic leadership and innovation: the moderating effect of environmental dynamism. European Journal of Innovation Management, 1-12. https://doi.org/https://doi.org/10.1108/EJIM-07-2018-0141

Ji, L.-J., Peng, K., Nisbett, R., \& psychology, s. (2000). Culture, control, and perception of relationships in the environment. Journal of personality, 78(5), 943. https://doi.org/https://doi.org/10.1037/0022-3514.78.5.94

Kaplan, L. D. (1994). Teaching intellectual autonomy: The failure of the critical thinking movement. Re-thinking reason: New perspectives in critical thinking, 205-220.

Kelloway, E. K., \& Gilbert, S. J. A. i. t. w. (2017). Does it matter who leads us?: The study of organizational leadership. An introduction to work organizational psychology: An international perspective, 192-211. https://doi.org/ https://doi.org/10.1002/9781119168058.ch11

Kim, H. S. (2002). We talk, therefore we think? A cultural analysis of the effect of talking on thinking. Journal of personality social psychology, 83(4), 828. https://doi.org/https://doi.org/10.1037/0022-3514.83.4.828

Korac-Kakabadse, N., Kouzmin, A., \& Korac-Kakabadse, A. (2001). Leadership renewal: Towards the philosophy of wisdom. International Review of Administrative Sciences, 67(2), 207-227. https://doi.org/https://doi.org/10.1177/0020852301672002

Ku, K. Y., \& Ho, I. T. (2010). Dispositional factors predicting Chinese students' critical thinking performance. Personality Individual Differences, 48(1), 54-58. https://doi.org/https://doi.org/10.1016/j.paid.2009.08.015

Lai, E. R. (2011). Critical thinking: A literature review.

Lau, W. K., Li, Z., \& Okpara, J. (2020a). An examination of three-way interactions of paternalistic leadership in $\begin{array}{lllll}\text { China. Asia Pacific Beview, } & \text { 32-49. }\end{array}$ https://doi.org/https://doi.org/10.1080/13602381.2019.1674031

Lau, W. K., Li, Z., \& Okpara, J. (2020b). An examination of three-way interactions of paternalistic leadership in $\begin{array}{lllll}\text { China. Asia Pacific Business } & \text { 26(1), }\end{array}$ https://doi.org/https://doi.org/10.1080/13602381.2019.1674031

Lau, W. K., Pham, L. N., \& Nguyen, L. D. (2019). Remapping the construct of paternalistic leadership. Leadership Organization Development Journal. https://doi.org/https://doi.org/10.1108/LODJ-01-2019-0028

Levin, S. J. P. P. (2004). Perceived group status differences and the effects of gender, ethnicity, and religion on social dominance orientation. 25(1), 31-48. https://doi.org/https://doi.org/10.1111/j.1467-9221.2004.00355.x

Lim, T. K. (1998). Ascertaining the critical thinking and formal reasoning skills of students. Research in Education, 59(1), 9-18. https://doi.org/https://doi.org/10.1177/003452379805900102

Lin, L., Li, P. P., \& Roelfsema, H. J. C. C. (2018). The traditional Chinese philosophies in inter-cultural leadership. Cross Cultural Strategic Management, 299-336. https://doi.org/10.1108/CCSM-01-2017-0001

Lin, T. T., Cheng, B. S., \& Chou, L. F. (2019). Paternalistic leadership: An indigenous concept with global significance. In Asian indigenous psychologies in the global context (pp. 115-138). Springer.

Liu, W., Zhu, R., \& Yang, Y. (2010). I warn you because I like you: Voice behavior, employee identifications, and transformational leadership. Journal of the Leadership Quarterly, 21(1), 189-202. https://doi.org/https://doi.org/10.1016/j.leaqua.2009.10.014

Mansur, J., Sobral, F., \& Goldszmidt, R. (2017). Shades of paternalistic leadership across cultures. Journal of World Business, 52(5), 702-713. https://doi.org/https://doi.org/10.1016/j.jwb.2017.06.003

Martin, J. R. (1992). Critical thinking for a humane world. The generalizability of critical thinking, 163-180.

Mason, M. (2008). Critical thinking and learning. Wiley Online Library. https://doi.org/https://doi.org/10.1111/j.1469-5812.2007.00343.x

Maxcy, S. (1985). The Democratic "Myth" and The Search for a Rational Concept of Education. Journal of Educational Philosophy, 17(1), 22-37. https://doi.org/https://doi.org/10.1111/j.1469-5812.1985.tb00113.x 
Misco, T. (2013). 'We do not talk about these things': the promises and challenges of reflective thinking and controversial issue discussions in a Chinese high school. Journal of Intercultural Education, 24(5), 401-416. https://doi.org/https://doi.org/10.1080/14675986.2013.842663

Moore, K. (2010). The three-part harmony of adult learning, critical thinking, and decision-making. Journal of Adult Education, 39(1), 1-10.

Moore, T. (2013). Critical thinking: Seven definitions in search of a concept. Studies in Higher Education, 38(4), 506-522. https://doi.org/https://doi.org/10.1080/03075079.2011.586995

Natale, S., \& Ricci, F. (2006). Critical thinking in organizations. Team Performance Management: An International Journal, 12(7), 272-277. https://doi.org/https://doi.org/10.1108/13527590610711822

Nickerson, R. S. (2007). Aspects of rationality: Reflections on what it means to be rational and whether we are. Psychology Press.

Nisbett, R. (2004). The geography of thought: How Asians and Westerners think differently... and why. Simon and Schuster.

Nisbett, R. E., Peng, K., Choi, I., \& Norenzayan, A. (2001). Culture and systems of thought: holistic versus $\begin{array}{llll}\text { analytic } & \text { Psychological } & \text { review, } & \text { 108(2), }\end{array}$ https://doi.org/https://doi.org/10.1037/0033-295X.108.2.291

Novelli Jr, L., \& Taylor, S. (1993). The context for leadership in 21st-century organizations: A role for critical thinking. American Behavioral $\quad$ Scientist, $\quad 37(1), \quad$ 139-147. https://doi.org/https://doi.org/10.1177/0002764293037001014

Paul, R. (1981). Teaching critical thinking in the" strong" sense: A focus on self-deception, world views, and a dialectical mode of analysis. Journal of Informal Logic, 4(2).

Paul, R., \& Elder, L. (2014). Critical thinking. Pearson. https://doi.org/https://doi.org/10.22329/il.v4i2.2766

Pellegrini, E. K., \& Scandura, T. A. (2008). Paternalistic leadership: A review and agenda for future research. Journal of management, 34(3), 566-593. https://doi.org/https://doi.org/10.1177/0149206308316063

Pellegrini, E. K., \& Scandura, T. A. J. J. O. M. (2008). Paternalistic leadership: A review and agenda for future research. 34(3), 566-593. https://doi.org/10.1177/0149206308316063

Pellegrini, E. K., Scandura, T. A., \& Jayaraman, V. (2010). Cross-cultural generalizability of paternalistic leadership: An expansion of leader-member exchange theory. Group Organization Management, 35(4), 391-420. https://doi.org/https://doi.org/10.1177/1059601110378456

Peng, K., \& Nisbett, R. E. (2000). Dialectical responses to questions about dialectical thinking. 1067-1068. https://doi.org/10.1037/0003-066X.55.9.1067

Phelan, A. M. (2001). The death of a child and the birth of practical wisdom. Studies in Philosophy and Education 20(1), 41-55. https://doi.org/https://doi.org/10.1023/A:1005295011215

Schön, D. A. (1938). The reflective practitioner. New York, 1083.

Shiraev, E. B., \& Levy, D. A. (2020). Cross-cultural psychology: Critical thinking and contemporary applications. Routledge.

Sidanius, J., \& Pratto, F. (2001). Social dominance: An intergroup theory of social hierarchy and oppression. Cambridge University Press.

Sidanius, J., Levin, S., Liu, J., \& Pratto, F. (2000). Social dominance orientation, anti-egalitarianism and the political psychology of gender: An extension and cross-cultural replication. European journal of social psychology, 30(1), 41-67. https://doi.org/https://doi.org/10.1002/(SICI)1099-0992(200001/02)30:1

Sigurðsson, G. (2017). Transformative critique: What Confucianism can contribute to contemporary education. Studies in Philosophy Education and Information Technologies, 36(2), 131-146. https://doi.org/0.1007/s11217-015-9502-3

Smeyers, P., \& Marshall, J. D. (1995). Philosophy and Education:: Accepting Wittgenstein's Challenge (Vol. 6). Springer.

Sposato, M. (2019). Understanding paternalistic leadership: how to work with Chinese leaders. Development Learning in Organizations: An International Journal, 33(6), 19-21. https://doi.org/https://doi.org/10.1108/DLO-12-2018-0169 
Taimur, S., \& Sattar, H. J. Q. E. (2020). Education for Sustainable Development and Critical Thinking Competency. 238-248. https://doi.org/https://doi.org/10.1007/978-3-319-95870-5

Tan, C. (2017a). A Confucian conception of critical thinking. Journal of Philosophy of Education, 51(1), 331-343. https://doi.org/ https://doi.org/10.1111/1467-9752.12228

Tan, C. (2017b). Teaching critical thinking: Cultural challenges and strategies in Singapore. British educational research journal, 43(5), 988-1002. https://doi.org/ https://doi.org/10.1002/berj.3295

Ten Dam, G., \& Volman, M. (2004). Critical thinking as a citizenship competence: teaching strategies. Learning and instruction, 14(4), 359-379.

Tian, J., \& Low, G. D. (2011). Critical thinking and Chinese university students: A review of the evidence. Language, Culture Curriculum 24(1), 61-76. https://doi.org/https://doi.org/10.1080/07908318.2010.546400

Tsui, A. S., Wang, H., Xin, K., Zhang, L., \& Fu, P. P. (2004). "Let a thousand flowers bloom”: Variation of leadership styles among Chinese CEOs. Journal of Organizational Dynamics, 33(1), 5-20. https://doi.org/10.1016/j.orgdyn.2

Tyler, T. R., \& Blader, S. L. J. P. (2003). The group engagement model: Procedural justice, social identity, and cooperative behavior. Journal of Personality social psychology review, 7(4), 349-361. https://doi.org/https://doi.org/10.1207/S15327957PSPR0704_07

Walker, P., \& Finney, N. (1999). Skill development and critical thinking in higher education. Journal of Teaching in Higher Education 4(4), 531-547. https://doi.org/https://doi.org/10.1080/1356251990040409

Waller, N. B. (2012). Critical thinking: Consider the verdict. Pearson Education, Inc. https://doi.org/https://doi.org/10.5840/teachphil198912245

Walters, K. S. (1994). Re-thinking reason: New perspectives in critical thinking. SUNY Press.

Wu, M. (2012). Moral leadership and work performance: Testing the mediating and interaction effects in China. . Chinese Management Studies, 6, 284-299. https://doi.org/https://doi.org/10.1108/17506141211236721

Wu, M., Huang, X., Li, C., \& Liu, W. (2012). Perceived interactional justice and trust-in-supervisor as mediators for paternalistic leadership. Journal of Management Organization Review, 8(1), 97-121. https://doi.org/10.1111/j.1740-8784.2011.00283.x

Yukawa, J. (2006). Co-reflection in online learning: Collaborative critical thinking as narrative. International Journal of Computer-Supported Collaborative Learning, 1(2), 203-228. https://doi.org/https://doi.org/10.1007/s11412-006-8994-9

\section{Copyrights}

Copyright for this article is retained by the author(s), with first publication rights granted to the journal.

This is an open-access article distributed under the terms and conditions of the Creative Commons Attribution license (http://creativecommons.org/licenses/by/4.0/). 